\title{
Papel del anestesiólogo en la pandemia de COVID-19
}

\section{Role of the anesthesiologist in the COVID-19 pandemic}

Dra. Idoris Cordero-Escobar*

E n la pasada epidemia de H1N1, aproximadamente entre los años 2008 y 2009, escribí para la web de Anestesiología un editorial en el que llamaba la atención, en particular, al gremio anestesiólogo cubano, sobre las medidas de protección a seguir tanto con el paciente, como con el personal médico y de enfermería, el cual podía recibir de urgencia en el quirófano a personas que estuvieran infectadas, así como las medidas a tomar para la protección y desinfección de los equipos utilizados y así evitar la transmisión de la enfermedad. Ha pasado más de una década, y hoy el mundo se enfrenta a un nuevo virus, que ha sobrepasado las expectativas de los científicos a nivel internacional. Esta contingencia sanitaria, inédita para esta generación, en la que el coronavirus acecha, requiere protección, pero también instrucción. El anestesiólogo, sin chovinismo alguno, es el médico más capacitado para el acceso a la vía respiratoria de los enfermos. Es quien vigila antes, durante y después del acto quirúrgico a los enfermos, y en cualquier momento de un procedimiento se expone a secreciones y fluidos. Es quien comparte con cirujanos e intensivistas el período intra- y postoperatorio, por lo que, sin lugar a dudas, está sujeto a riesgo de contraer la enfermedad.

Alhazzani y colaboradores afirmaron que los anestesiólogos constituyen una población de riesgo muy elevado, por estar en contacto directo con las secreciones de pacientes durante la realización de procedimientos invasivos y la colocación de dispositivos avanzados en la vía respiratoria. El Dr. Xavier Onrubia adaptó el protocolo del Departamento de Anestesiología de la Universidad de Toronto, así como las publicaciones actualizadas de la OMS y del Ministerio de Sanidad Español. En él recomienda que el personal que atiende infectados por coronavirus, que requieren acceso a la vía respiratoria, deben usar equipos de protección, entre los que incluye: el uso de mascarillas de alta eficacia (N95, FFP3 o FFP2), protección ocular con gafas de armadura integral o protector facial completo, guantes, botas y batas impermeables desechables. Además, sugiere que la intubación se realizará por el profesional disponible más experimentado en el abordaje de la vía respiratoria.

El incremento de esta infección a escala global, y en América en particular, podría hacernos reflexionar sobre algunas recomendaciones ante un paciente sospechoso o confirmado de infección por COVID-19, que requiere tratamiento quirúrgico de urgencia o emergencia. En la mayoría de los hospitales de Europa y EUA, dejaron esta responsabilidad a los anestesiólogos, por lo que cuentan con el mayor número de infectados y muertos de todo el gremio. En una entrevista realizada por el diario Corriere della Sera, de Italia, el Dr. Christian Sarolli declaró: "No se imaginan lo que está pasando. Hay que elegir a quién tratar y a quién no, según la edad y las condiciones de salud, que ayuden a la recuperación, como en situaciones de guerra..."

Al leer dicha entrevista, recordé el lema de la Confederación Latinoamericana de Sociedades de Anestesiología (CLASA): Deorum Ars, es decir, «Arte de los Dioses» y creo que realmente la especialidad lo es. A modo de conclusión, sirva este editorial para rendir un tributo de admiración y respeto a todos los héroes anónimos, anestesiólogos del mundo, que una vez más han expuesto su vida en aras de ayudar al prójimo.
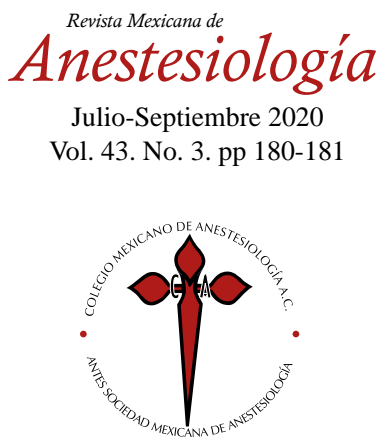

* Especialista en Anestesiología y Reanimación. Profesora e Investigadora Titular. Doctora en Ciencias. Servicio de Anestesiología y Reanimación. Hospital «Hermanos Ameijeiras». La Habana, Cuba.

Solicitud de sobretiros: Dra. Idoris Cordero-Escobar Servicio de Anestesiología y Reanimación, 5to piso, Hospital «Hermanos Ameijeiras».

San Lázaro Núm. 701, entre Belascoaín y Marqués González, Centro Habana, 10300, La Habana, Cuba. E-mail: ice@infomed.sld.cu ORCID: http://orcid. org/0000-0001-9877-3113 


\section{LECTURAS RECOMENDADAS}

- World Health Organization. Statement on the second meeting of the International Health. Regulations. Emergency Committee regarding the outbreak of novel coronavirus (2019-nCoV). 2020. Disponible en: https://www.who.int/newsroom/detail/30-01-2020-statement-onthe-second-meeting-of-theinternational-health-regulations-(2005)emergency-committeeregarding-the-outbreak-ofnovelcoronavirus(2019-ncov)

- Loftus RW, Dexter F, Robinson ADM. High-risk Staphylococcus aureus transmission in the operating room: A call for widespread improvements in perioperative hand hygiene and patient decolonization practices. Am J Infect Control. 2018;46:1134-1141.

- Wax RS, Christian MD. Practical recommendations for critical care and anesthesiology teams caring for novel coronavirus (2019-nCoV) patients. Can J Anaesth. 2020;67:568-576. doi: 10.1007/s12630-02001591-x.
- Wen X, Li Y. Anesthesia procedure of emergency operation for patients with suspected or confirmed COVID-19. Surg Infect (Larchmt). 2020;21:299. doi: 10.1089/sur.2020.040.

- Aparicio Morales AI. Riesgo laboral en Anestesiología ante posible infección por coronavirus. Rev Cubana Anest Rean. 2020;20:e643.

- Alhazzani W, Møller MH, Arabi YM, Loeb M, Gong MN, Fan E, et al. Surviving Sepsis Campaign: guidelines on the management of critically ill adults with Coronavirus Disease 2019 (COVID-19). Intensive Care Med. 2020;46:854-887. doi: 10.1007/s00134-020-06022-5.

- Onrubia X. Manejo clínico de la infección respiratoria aguda grave presuntamente causada por el nuevo coronavirus (2019-nCoV). Orientaciones provisionales. 28 de enero de 2020. Disponible en: https://apps.who.int/iris/ bitstream/handle/10665/330938/WHO-nCoV-Clinical-2020.3-spa.pdf

- Sarolli C. Entrevista. Diario Corriere della Sera. 2020. Disponible en: www.infobase.com. 